Western University

Scholarship@Western

$10-13-2020$

\title{
Transesterification of Poly(ethyl glyoxylate): A Route to Structurally Diverse Polyglyoxylates
}

\author{
Rebecca E. Yardley \\ The University of Western Ontario \\ Amir Rabiee Kenaree \\ The University of Western Ontario \\ Xiaoli Liang \\ The University of Western Ontario \\ Elizabeth R. Gillies \\ The University of Western Ontario
}

Follow this and additional works at: https://ir.lib.uwo.ca/chempub

Part of the Chemistry Commons

\section{Citation of this paper:}

Yardley, Rebecca E.; Rabiee Kenaree, Amir; Liang, Xiaoli; and Gillies, Elizabeth R., "Transesterification of Poly(ethyl glyoxylate): A Route to Structurally Diverse Polyglyoxylates" (2020). Chemistry Publications. 190.

https://ir.lib.uwo.ca/chempub/190 


\section{Transesterification of Poly(ethyl glyoxylate): A Route To Structurally Diverse Polyglyoxylates}

Rebecca E. Yardley, ${ }^{\dagger}$ Amir Rabiee Kenaree, ${ }^{\dagger}$ Xiaoli Liang, ${ }^{\dagger}$ and Elizabeth R. Gillies ${ }^{*}{ }^{* \sharp}$

† Department of Chemistry and Centre for Advanced Materials and Biomaterials Research, The University of Western Ontario, 1151 Richmond St., London, Ontario, Canada N6A 5B7.

* Department of Chemical and Biochemical Engineering, The University of Western Ontario, 1151 Richmond St., London, Ontario, Canada N6A 5B9.

Correspondence to: E. R. Gillies (E-mail: egillie@uwo.ca)

For Table of Contents use only

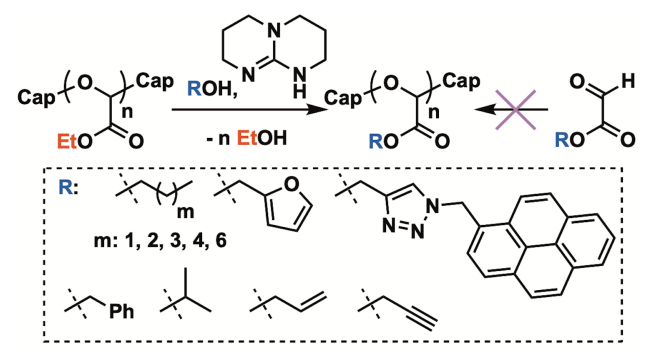




\section{ABSTRACT}

Polyglyoxylates are a class of self-immolative polymers that depolymerize in solution and the solid-state. The glyoxylic acid degradation product is a metabolite in the glyoxylate cycle, and can also be processed in the liver in humans, making polyglyoxylates attractive for applications in the environment and in medicine. While expanding the scope of available polyglyoxylates would enable new properties and applications, highly pure glyoxylate monomers are required for polymerization, and this level of purity is difficult to achieve for many potential monomers. To address this challenge, we report here the 1,5,7-triazabicyclo[4.4.0]dec-5-ene (TBD)-catalyzed postpolymerization transesterification of poly(ethyl glyoxylate) (PEtG) as a general strategy for the synthesis of directly-inaccessible polyglyoxylates. Using a new end-capping strategy, PEtG compatible with the transesterification reaction was developed. $n$-Propanol, $i$-propanol, $n$-butanol, $t$-butanol, $n$-pentanol, $n$-hexanol, $n$-octanol, and benzyl alcohol were employed and the reactivities of these different alcohols were investigated. The resulting polyglyoxylates were characterized chemically and their thermal properties were compared. In all cases, the transesterified polyglyoxylates retained the stimuli-responsive depolymerization properties of the parent PEtG. In addition, functional polyglyoxylates based on allyl, propargyl and furfuryl esters, which are suitable for subsequent click reactions, were prepared. The propargyl-functionalized polyglyoxylate was used to conjugate pyrene, which underwent a change in fluorescent properties upon depolymerization.

\section{INTRODUCTION}

Stimuli-responsive polymers are of significant interest both fundamentally and for a wide range of applications such as sensors, ${ }^{1}$ actuators, ${ }^{2}$ and drug delivery vehicles. ${ }^{3}$ Degradable polymers have also been garnering attention in recent years as replacements for non-degradable polymers to 
address challenges such as plastic pollution. ${ }^{4-5}$ They are also widely used in biomedical applications ranging from therapeutics ${ }^{6-7}$ to regenerative medicine. ${ }^{8-9}$ Self-immolative polymers (SIPs) are a growing class of degradable, stimuli-responsive polymers. ${ }^{10-11}$ Unlike degradable polymers containing multiple stimuli-responsive linkers such as $\mathrm{pH}$-sensitive acetals, ${ }^{12-13}$ or photochemically cleavable $o$-nitrobenzyl moieties in their backbones, ${ }^{14}$ SIPs are characterized by their ability to undergo complete, end-to-end depolymerization by a reaction cascade, following a single bond cleavage in the polymer backbone or between an end-cap and the polymer terminus. ${ }^{11}$

Thus far, the most widely explored SIPs include polycarbamates, ${ }^{15-16}$ poly(benzyl ether)s, ${ }^{17}$ polyphthalaldehydes, ${ }^{18-19}$ and polyglyoxylates (PGs). ${ }^{20}$ They have been explored for applications such as sensors, ${ }^{15,21}$ transient electronics, ${ }^{22-24}$ drug delivery vehicles, ${ }^{25-27}$ and in recyclable plastics and composites. ${ }^{28-30}$ In addition, new depolymerizable polymers including poly(benzyl ester)s $\mathrm{s}^{31}$ polycarboxypyrroles, ${ }^{32}$ and polyglyoxylamides ${ }^{33}$ continue to be developed to achieve different properties and meet the requirements for additional applications such as photolithography ${ }^{31}$ and kinetic hydrate inhibition in oil and gas lines. ${ }^{34}$

SIP backbones such as polycarbamates, ${ }^{15-16}$ polycarbonates, ${ }^{35-36}$ poly(benzyl ester)s,${ }^{31}$ and polycarboxypyrroles, ${ }^{32}$ have been synthesized by step-growth polymerization methods. These methods have allowed for the incorporation of many different pendent functional groups, but typically result in relatively low degrees of polymerization $\left(\mathrm{DP}_{\mathrm{n}}\right)$. On the other hand polyphthalaldehydes, ${ }^{19}, 37-38$ poly(benzyl ether)s, ${ }^{17}$ and polyglyoxylates ${ }^{20}, 39-40$ have been synthesized by chain addition polymerization methods, leading to higher $\mathrm{DP}_{\mathrm{n}}$, but with less functional group tolerance due to their cationic or anionic synthesis mechanisms. Consequently, far fewer functionalized versions of these SIPs have been reported. ${ }^{20,41-45}$ 
Polyglyoxylates are an attractive class of SIPs as they depolymerize back to their corresponding glyoxylate monomers, which can potentially be repolymerized, ${ }^{29}$ or degraded to glyoxylic acid hydrate through hydration and hydrolysis (Figure 1). ${ }^{39}$ Glyoxylic acid is a metabolic intermediate in the glyoxylate cycle, which occurs in bacteria, plants, fungi, and other organisms, so depending on the pendent alcohol, polyglyoxylate degradation products should be relatively non-toxic in the environment. ${ }^{46}$ Furthermore, glyoxylic acid is a metabolic intermediate in humans, which can be processed in the liver, so it is expected to be well tolerated in vivo, at least at low concentrations. ${ }^{47}$ However, a challenge in synthesizing polyglyoxylates is that highly pure glyoxylate monomers are required to achieve high molar mass polymers.

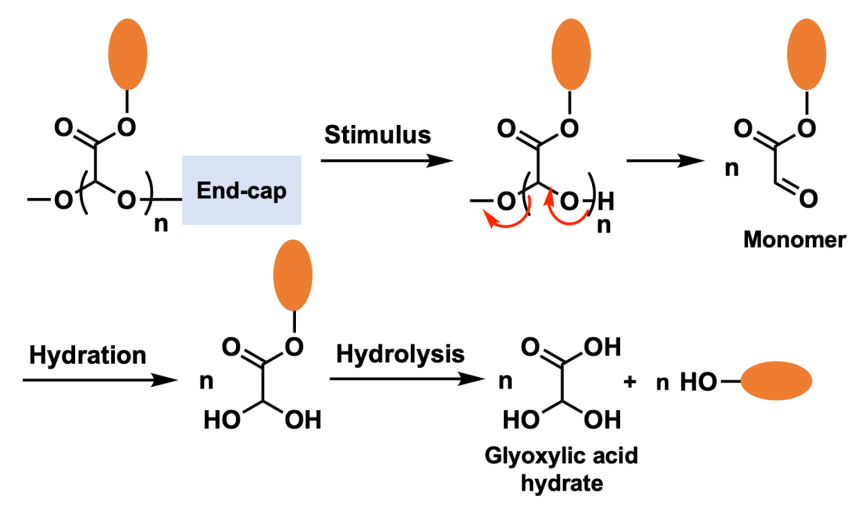

Figure 1. Depolymerization of a polyglyoxylate back to monomer after end-cap cleavage by a stimulus, followed by hydration, then hydrolysis to glyoxylic acid hydrate and the corresponding alcohol.

Recently, we reported the anionic polymerization of ethyl glyoxylate (EtG) and an optimized method for the purification of EtG to levels required for controlled polymerization. ${ }^{40}$ To crack the oligomers and eliminate the hydrate species to yield ultrapure EtG, the use of heat and $\mathrm{P}_{2} \mathrm{O}_{5}$ is required. For EtG, which has a boiling point of $110{ }^{\circ} \mathrm{C}$, it was possible to develop thermal distillation conditions for its separation from $\mathrm{H}_{3} \mathrm{PO}_{4}$ (boiling point $158{ }^{\circ} \mathrm{C}$ ), the byproduct of the reaction of $\mathrm{P}_{2} \mathrm{O}_{5}$ with the hydrate species. However, for many other monomers, compatibility with hot $\mathrm{H}_{3} \mathrm{PO}_{4}$ 
and/or separation from $\mathrm{H}_{3} \mathrm{PO}_{4}$ are problematic, leading to lower purity monomer. Polymerization with of lower purity monomer leads to polymers with low $\mathrm{DP}_{\mathrm{n}}{ }^{20,45}$ In addition, we have found that the best route for the preparation of new glyoxylate monomers is the ozonolysis of the corresponding fumarate derivatives. ${ }^{20}$ Functional groups such as alkenes and alkynes are not readily compatible with the ozonolysis reaction. Thus, the synthesis of polyglyoxylates with a diverse range of pendent functional groups remains a significant synthetic challenge.

An alternative approach to the polymerization of different monomers is postpolymerization modification. ${ }^{48}$ Recently, use of the organocatalyst 1,5,7-triazabicyclo[4.4.0]dec-5ene (TBD) for the transesterification of polyacrylates was reported. ${ }^{49}$ Inspired by this finding, we implemented TBD-catalyzed transesterification of PEtG with various alcohols to expand the library of accessible polyglyoxylates. The stability of the depolymerizable PEtG backbone and end-cap to TBD catalyzed transesterification was investigated. Then, a series of different alcohols were used in transesterification reactions to afford polyglyoxylates with pendent esters ranging from propyl to octyl, along with functional versions including allyl, furfuryl, and propargyl. The thermal properties of the different derivatives were studied. Triggerable depolymerization behavior was retained in all of the transesterified polymers. Furthermore, the propargyl version was used to install pyrene, providing a polymer that underwent a change in its fluorescent properties upon depolymerization.

\section{EXPERIMENTAL}

\section{General materials}

$\mathbf{P E t G}_{\text {carbonate }}$ was synthesized as previously reported, providing an $\mathrm{M}_{\mathrm{n}}$ of $27.6 \mathrm{~kg} / \mathrm{mol}, \mathrm{M}_{\mathrm{w}}=35.6$ $\mathrm{kg} / \mathrm{mol}$, and $\oslash=1.29 .{ }^{40}$ TBD (freshly opened or dried via toluene azeotrope), 2-nitrobenzyl alcohol, and 1-(azidomethyl)pyrene were obtained from AK Scientific Inc. and used as received. 
Lithium bis(trimethylsilyl)amide [(TMS) $\left.{ }_{2} \mathrm{NLi}\right], n$-pentanol, $n$-hexanol, benzyl alcohol (BnOH), propargyl alcohol, furfuryl alcohol, $n$-BuLi (2.5 M in hexanes), benzyl chloromethyl ether (technical, $\sim 60 \%$ ), benzyl chloroformate, $\mathrm{CaH}_{2}$, and (+)-sodium L-ascorbate were obtained from Sigma-Aldrich and used as received. Allyl alcohol, $n$-butanol, and copper (II) sulfate were obtained from Alfa Aesar and used as received. EtG (ca. 50\% in toluene) was purchased from Alfa Aesar and purified as previously reported. ${ }^{40} n$-Propanol, $i$-propanol, $n$-octanol, pentane, acetone, $\mathrm{CDCl}_{3}$, magnesium sulfate, and hydrochloric acid were obtained from Caledon Laboratories and used as received. Anhydrous ethanol was obtained from Commercial Alcohols and used as received. Toluene was obtained from Caledon Laboratories and distilled over sodium using benzophenone as an indicator. $\mathrm{NEt}_{3}$ was obtained from Caledon Laboratories and stirred over $\mathrm{CaH}_{2}$ for $16 \mathrm{~h}$ before thermal distillation. $\mathrm{N}, \mathrm{N}$-Dimethylformamide (DMF) was obtained from a PureSolv MD 5 solvent purification system equipped with aluminum oxide columns. Column chromatography was performed using silica gel (0.063-0.200 mm particle size, 70-230 mesh) from SiliCycle. Ultrapure deionized water was obtained from a Barnstead EASYpure II system.

\section{General methods}

All reactions were performed under a $\mathrm{N}_{2}$ atmosphere using flame or oven-dried glassware. Dialyses were performed using Spectra/Por regenerated cellulose membranes. ${ }^{1} \mathrm{H}$ NMR spectra were obtained at $400 \mathrm{MHz}$ using a Varian INOVA spectrometer. Chemical shifts ( $\delta$ ) are given in parts per million (ppm) and were calibrated against the residual solvent signals $\mathrm{CDCl}_{3}$ (7.27). Coupling constants $(J)$ are given in Hz. Size exclusion chromatography (SEC) for molar mass analysis was conducted using THF solutions of polymers at concentrations of $c a .5 \mathrm{mg} / \mathrm{mL}$. The samples were analyzed using a Viscotek GPCmax VE 2001 SEC instrument equipped with an Agilent PolyPore guard column (PL1113-1500) and two sequential Agilent PolyPore SEC columns (molar mas 
range $200-2,000,000 \mathrm{~g} / \mathrm{mol} ;$ PL1113-6500) regulated at a temperature of $30^{\circ} \mathrm{C}$. Signal responses were measured using a Viscotek VE 3580 RI detector and molar masses were determined by conventional calibrations using poly(methyl methacrylate) (PMMA) standards purchased from Viscotek. Thermogravimetric analysis (TGA) was performed using a TA Instruments Q50 thermogravimetric analyzer. Samples were placed in a platinum pan and heated at a rate of 10 ${ }^{\circ} \mathrm{C} /$ min from 25 to $1000{ }^{\circ} \mathrm{C}$ under a flow of nitrogen $(60 \mathrm{~mL} / \mathrm{min})$. Differential scanning calorimetry (DSC) thermograms were acquired using a TA Instruments DSC Q20 instrument. The polymer samples were placed in aluminum Tzero pans and heated from room temperature to maximum temperatures, which were at least $20^{\circ} \mathrm{C}$ below the onset of decomposition, at $10{ }^{\circ} \mathrm{C} / \mathrm{min}$ under a flow of nitrogen $(50 \mathrm{~mL} / \mathrm{min})$, and cooled to $-70{ }^{\circ} \mathrm{C}$ at $10{ }^{\circ} \mathrm{C} / \mathrm{min}$, before they underwent two additional heating/cooling cycles. Thermal data were obtained from the second full heating cycle. Infrared (IR) spectra were obtained on a PerkinElmer Spectrum Two FTIR Spectrometer using the attenuated total reflectance accessory.

\section{Synthesis of PEtG $_{\text {ether }}$}

In a Schlenk flask, an $n$-BuLi solution $(100 \mu \mathrm{L}, 2.5 \mathrm{M}$ in hexanes, $0.25 \mathrm{mmol})$ was combined with dry toluene $(20 \mathrm{~mL})$ and then freshly distilled $\mathrm{EtG}(5.0 \mathrm{~mL}, 50 \mathrm{mmol})$ was rapidly added at $20^{\circ} \mathrm{C}$. The resulting solution was vigorously stirred for 15 minutes. It was then cooled to $-20{ }^{\circ} \mathrm{C}$ and stirred for $10 \mathrm{~min}$ before the addition of $\mathrm{NEt}_{3}(0.3 \mathrm{~mL}, 2 \mathrm{mmol})$ and stirring for another $10 \mathrm{~min}$. Benzyl chloromethyl ether $(1.0 \mathrm{~mL}, 4.3 \mathrm{mmol})$ was rapidly added and the resulting mixture was stirred for $3 \mathrm{~h}$ at $-20{ }^{\circ} \mathrm{C}$, before sealing the flask under $\mathrm{N}_{2}$ gas, and transferring it into a $-20{ }^{\circ} \mathrm{C}$ freezer where it was kept for $21 \mathrm{~h}$. The polymerization mixture was then precipitated into $-20{ }^{\circ} \mathrm{C}$ methanol $(250 \mathrm{~mL})$. After decanting the solvent, the resulting residue was dried under vacuum. 
Yield $=2.5 \mathrm{~g}, 50 \% .{ }^{1} \mathrm{H}$ NMR (400 MHz, $\left.\mathrm{CDCl}_{3}, \delta\right):$ 5.75-5.48 (m, $\left.122 \mathrm{H}\right), 4.27-4.03(\mathrm{~m}, 247 \mathrm{H})$, $1.32-1.28(\mathrm{~m}, 369 \mathrm{H}), 0.89$ (br s, $3 \mathrm{H})$. SEC: $\mathrm{M}_{\mathrm{n}}=14.0 \mathrm{~kg} / \mathrm{mol}, \mathrm{M}_{\mathrm{w}}=18.1 \mathrm{~kg} / \mathrm{mol}, Ð=1.29$.

\section{Synthesis of PEtGuv}

In a Schlenk flask and at $20{ }^{\circ} \mathrm{C}$, 2-nitrobenzyl alcohol (153 mg, $\left.1.0 \mathrm{mmol}\right)$ and (TMS) $2 \mathrm{NLi}(167$ $\mathrm{mg}, 1.0 \mathrm{mmol})$ were combined in dry toluene $(80 \mathrm{~mL})$ and stirred for $5 \mathrm{~s}$, before the rapid addition of freshly distilled EtG $(20.0 \mathrm{~mL}, 200 \mathrm{mmol})$. The resulting solution was then cooled to $-20{ }^{\circ} \mathrm{C}$ and vigorously stirred for $15 \mathrm{~min}$. $\mathrm{NEt}_{3}(1.2 \mathrm{~mL}, 9 \mathrm{mmol})$ was added and the solution was stirred for another $20 \mathrm{~min}$. Benzyl chloromethyl ether $(4.0 \mathrm{~mL}, 17 \mathrm{mmol})$ was instantly added and the resulting mixture was stirred for $3 \mathrm{~h}$ at $-20{ }^{\circ} \mathrm{C}$, before sealing the flask under $\mathrm{N}_{2}$ gas, and transferring it into a $-20^{\circ} \mathrm{C}$ freezer where it was kept for $21 \mathrm{~h}$. The polymerization mixture was then precipitated into methanol $(1.0 \mathrm{~L})$. The solvent was decanted and the resulting residue was dried under vacuum. Yield $=16 \mathrm{~g}, 80 \% .{ }^{1} \mathrm{H}$ NMR $\left(400 \mathrm{MHz}, \mathrm{CDCl}_{3}, \delta\right): 8.10(\mathrm{~s}, 1 \mathrm{H}), 7.87(\mathrm{~d}, J=$ $16 \mathrm{~Hz}, 1 \mathrm{H}), 7.67$ (d, J=8 Hz, 1H), 7.46 (s, $1 \mathrm{H}), 5.80-5.48(\mathrm{~m}, 226 \mathrm{H}), 5.14(\mathrm{~s}, 2 \mathrm{H}), 4.99$ (s, 2 H), 4.20-4.13 (m, $458 \mathrm{H}), 1.37-1.19(\mathrm{~m}, 690 \mathrm{H}) . \mathrm{SEC}: \mathrm{M}_{\mathrm{n}}=24.1 \mathrm{~kg} / \mathrm{mol}, \mathrm{M}_{\mathrm{w}}=29.9 \mathrm{~kg} / \mathrm{mol}, Ð$ $=1.24$.

\section{Study of polyglyoxylate stability under the transesterification conditions}

In a Schlenk flask, PEtG carbonate, PEtGether, or PEtGuv $(150 \mathrm{mg}, 1.5 \mathrm{mmol}$ of ethyl ester units, 1.0 equiv.) toluene $(5 \mathrm{~mL})$, ethanol $(0.87 \mathrm{~mL}, 15 \mathrm{mmol}, 10$ equiv.), and TBD (44 mg, $0.29 \mathrm{mmol}$, 0.2 equiv.) were combined and degassed for $15 \mathrm{~min}$. The solution was then divided between five pressure tubes in a glovebox, and heated at $100{ }^{\circ} \mathrm{C}$ outside the glovebox for $0,1,3$, 6, or $24 \mathrm{~h}$. After cooling to $20^{\circ} \mathrm{C}$, the crude samples were dried in vacuo and analyzed by SEC.

\section{General procedures for the transesterification reactions}


For ethanol, $\boldsymbol{n}$-propanol, $\boldsymbol{i}$-propanol, and $\boldsymbol{n}$-butanol (volatile alcohols). Inside a septum sealed pressure tube, PEtGuv (200 mg, $2.0 \mathrm{mmol}$ of ethyl ester units, 1.0 equiv.) was combined with an alcohol (10 equiv.) and dry toluene $(4.0 \mathrm{~mL})$. The resulting solution was degassed by bubbling $\mathrm{N}_{2}$ gas through it for $20 \mathrm{~min}$. TBD (55 $\mathrm{mg}, 0.39 \mathrm{mmol}, 0.2$ equiv.) was then added and the tube was rapidly sealed using a Teflon cap. The reaction mixture was heated at $100{ }^{\circ} \mathrm{C}$ for $17 \mathrm{~h}$.

For the remaining non-volatile alcohols. Inside a Schlenk tube PEtG $\mathbf{U v}$ (200 mg, 2.0 mmol of ethyl ester units, 1.0 equiv.) was combined with an alcohol (10 equiv. or 0.5 equiv.) and dry toluene (4.0 mL). The resulting solution was degassed by bubbling $\mathrm{N}_{2}$ gas through it for $20 \mathrm{~min}$, before adding TBD (55 mg, $0.39 \mathrm{mmol}, 0.2$ equiv.). The reaction mixture was heated at $100{ }^{\circ} \mathrm{C}$ for $17 \mathrm{~h}$ under a constant nitrogen flow ( $c a .5 \mathrm{~mL} / \mathrm{min}$ ) while it was being vented, using a needle to remove the ethanol that was produced during the reaction.

\section{General work up procedure}

After cooling to $20^{\circ} \mathrm{C}$, the crude products were diluted with $\mathrm{CH}_{2} \mathrm{Cl}_{2}(15 \mathrm{~mL})$ and washed with an $\mathrm{HCl}$ solution $(\mathrm{pH}=2 ; 3 \times 20 \mathrm{~mL})$. The organic layer was dried with $\mathrm{MgSO}_{4}$, filtered, and concentrated in vacuo. The pure polymer was isolated by three precipitations from $\mathrm{CH}_{2} \mathrm{Cl}_{2}$ solution $(1 \mathrm{~mL})$ into pentane $(50 \mathrm{~mL})$ or dialysis against acetone (molecular weight-cutoff (MWCO): 10 $\mathrm{kg} / \mathrm{mol}, 1 \mathrm{~L}$, two rounds: 8 and $16 \mathrm{~h}$ ). The resulting product was dried under vacuum.

PnPrG. From $n$-propanol (1.5 mL, $20 \mathrm{mmol}, 10$ equiv.). The product was purified by precipitation. Conversion: >99\%. Yield: 57\%. ${ }^{1} \mathrm{H}$ NMR (400 $\left.\mathrm{MHz} \mathrm{CDCl}_{3}, \delta\right): 5.85-5.50$ (m, $\left.1 \mathrm{H}\right), 4.20-4.03$ (m, 2 H), 1.72-1.65 (m, 2 H), 0.99-0.87 (m, 3 H). SEC: $M_{n}=24.1 \mathrm{~kg} / \mathrm{mol}, \mathrm{M}_{\mathrm{w}}=44.3 \mathrm{~kg} / \mathrm{mol}, \emptyset=$ 1.77.

PiPrG. From $i$-propanol (1.5 mL, $20 \mathrm{mmol}, 10$ equiv.). The product was purified by precipitation. Conversion: 70\%. Yield 62\%. ${ }^{1} \mathrm{H}$ NMR (400 $\left.\mathrm{MHz} \mathrm{CDCl}_{3}, \delta\right): 5.74-5.44$ (m, 1.0 H), 5.07-4.95 
(m, $0.7 \mathrm{H}), 4.26-4.15(\mathrm{~m}, 0.5 \mathrm{H}), 1.34-1.21(\mathrm{~m}, 5.5 \mathrm{H}) . \mathrm{SEC}: \mathrm{M}_{\mathrm{n}}=22.9 \mathrm{~kg} / \mathrm{mol}, \mathrm{M}_{\mathrm{w}}=35.8 \mathrm{~kg} / \mathrm{mol}$, $Ð=1.56$.

PnBuG. From $n$-butanol (1.8 mL, $20 \mathrm{mmol}, 10$ equiv.). The product was purified by precipitation. Conversion: > $99 \%$. Yield: 70\%. ${ }^{1} \mathrm{H}$ NMR (400 MHz, $\mathrm{CDCl}_{3}, \delta$ ): 5.74-5.47 (m, $\left.1 \mathrm{H}\right), 4.20-4.06$ (m, 2 H), 1.69-1.58 (m, 2 H), 1.44-1.32 (m, 2 H), 0.97-0.86 (m, 3 H). SEC: $\mathrm{M}_{\mathrm{n}}=22.6 \mathrm{~kg} / \mathrm{mol}$, $\mathrm{M}_{\mathrm{w}}=35.0 \mathrm{~kg} / \mathrm{mol}, \nexists=1.55$.

PnPenG. From $n$-pentanol (2.2 mL, $20 \mathrm{mmol}, 10$ equiv.). The product was purified by dialysis. Conversion: $>99 \%$. Yield: $64 \% .{ }^{1} \mathrm{H}$ NMR (400 MHz, $\mathrm{CDCl}_{3}, \delta$ ): 5.75-5.45 (m, $\left.1 \mathrm{H}\right), 4.20-4.03$ (m, 2 H), 1.73-1.61 (m, 2 H), 1.40-1.25 (m, 4 H), 0.94-0.85 (m, 3 H). SEC: $\mathrm{M}_{\mathrm{n}}=22.6 \mathrm{~kg} / \mathrm{mol}$, $\mathrm{M}_{\mathrm{w}}=33.2 \mathrm{~kg} / \mathrm{mol}, \emptyset=1.46$.

PnHexG. From $n$-hexanol $(2.5 \mathrm{~mL}, 20 \mathrm{mmol}, 10$ equiv.). The product was purified by dialysis. Conversion: $>99 \%$. Yield: $62 \% .{ }^{1} \mathrm{H}$ NMR (600 MHz, $\left.\mathrm{CDCl}_{3}, \delta\right): 5.71-5.45(\mathrm{~m}, 1 \mathrm{H}), 4.22-4.03$ (m, 2 H), 1.69-1.63 (m, 2 H), 1.38-1.22 (m, 6 H), 0.91-0.83 (m, 3 H). SEC: $\mathrm{M}_{\mathrm{n}}=21.8 \mathrm{~kg} / \mathrm{mol}$, $\mathrm{M}_{\mathrm{w}}=37.6 \mathrm{~kg} / \mathrm{mol}, \oslash=1.72$.

PnOctG. From $n$-octanol ( $3.1 \mathrm{~mL}, 20 \mathrm{mmol}, 10$ equiv.). The product was purified by dialysis. Conversion: >99\%. Yield: 61\%. ${ }^{1} \mathrm{H}$ NMR (600 MHz, $\left.\mathrm{CDCl}_{3}, \delta\right): 5.80-5.48(\mathrm{~m}, 1 \mathrm{H}), 4.22-4.07$ (m, 2 H), 1.68-1.58 (m, 2 H), 1.42-1.22 (m, 10 H), 0.93-0.88 (m, 3 H). SEC: $\mathrm{M}_{\mathrm{n}}=28.9 \mathrm{~kg} / \mathrm{mol}$, $\mathrm{M}_{\mathrm{w}}=54.1 \mathrm{~kg} / \mathrm{mol}, \emptyset=1.87$.

PBnG. From benzyl alcohol $(2.3 \mathrm{~mL}, 20 \mathrm{mmol}, 10$ equiv.). The product was purified by precipitation. Conversion: $>99 \%$. Yield: $67 \%$. ${ }^{1} \mathrm{H}$ NMR (400 MHz, $\mathrm{CDCl}_{3}, \delta$ ): 7.40-7.05 (m, 5 H), 5.80-5.47 (m, 1 H), 5.05-4.78 (m, 2 H). SEC: $\mathrm{M}_{\mathrm{n}}=18.8 \mathrm{~kg} / \mathrm{mol} \mathrm{M}_{\mathrm{w}}=29.4 \mathrm{~kg} / \mathrm{mol}, \nexists=1.57$. PFuG. From furfuryl alcohol $(0.22 \mathrm{~mL}, 2.5 \mathrm{mmol}, 0.50$ equiv. $)$. The product was purified by dialysis. Conversion: 15\%. Yield: 59\%. ${ }^{1} \mathrm{H}$ NMR (400 MHz, $\left.\mathrm{CDCl}_{3}, \delta\right): 7.43-7.38$ (m, $\left.0.16 \mathrm{H}\right)$, 
6.50-6.43 (m, 0.15 H), 6.35-6.32 (m, 0.15 H), 5.70-5.51 (m, $1.0 \mathrm{H})$, 5.19-5.13 (m, 0.3 H), 4.29-4.14 (m, $1.7 \mathrm{H}), 1.33-1.26(\mathrm{~m}, 2.6 \mathrm{H})$. SEC: $\mathrm{M}_{\mathrm{n}}=21.7 \mathrm{~kg} / \mathrm{mol}, \mathrm{M}_{\mathrm{w}}=35.8 \mathrm{~kg} / \mathrm{mol}, D=1.65$.

PAllG. From allyl alcohol $(0.17 \mathrm{~mL}, 2.5 \mathrm{mmol}, 0.50$ equiv. $)$. The product was purified by dialysis. Conversion: 25\%. Yield: $71 \%$. ${ }^{1} \mathrm{H}$ NMR (400 MHz, $\mathrm{CDCl}_{3}, \delta$ ): 5.98-5.89 (m, 0.26 H), 5.75-5.48 (m, $1.0 \mathrm{H}), 5.36-5.32(\mathrm{~m}, 0.25 \mathrm{H}), 5.24-5.22(\mathrm{~m}, 0.25 \mathrm{H}), 4.70-4.62(\mathrm{~m}, 0.54 \mathrm{H}), 4.27-4.17(\mathrm{~m}$, $1.6 \mathrm{H}), 1.32-1.25(\mathrm{~m}, 2.4 \mathrm{H})$. SEC: $\mathrm{M}_{\mathrm{n}}=20.2 \mathrm{~kg} / \mathrm{mol}, \mathrm{M}_{\mathrm{w}}=33.4 \mathrm{~kg} / \mathrm{mol}, \nexists=1.51$.

PPG. From propargyl alcohol $(0.15 \mathrm{~mL}, 2.5 \mathrm{mmol}, 0.5$ equiv.). The product was purified by dialysis. Conversion: 26\%. Yield: $60 \% .{ }^{1} \mathrm{H}$ NMR (400 MHz, $\left.\mathrm{CDCl}_{3}, \delta\right): 5.81-5.48$ (m, $\left.1.0 \mathrm{H}\right)$, 4.82-4.76 (m, 0.54 H), 4.27-4.18 (m, 1.5 H), 2.62-2.47 (m, 1.0 H), 1.35-1.28 (m, 2.4 H). SEC: $\mathrm{M}_{\mathrm{n}}=20.2 \mathrm{~kg} / \mathrm{mol}, \mathrm{M}_{\mathrm{w}}=35.8 \mathrm{~kg} / \mathrm{mol}, \oslash=1.65$.

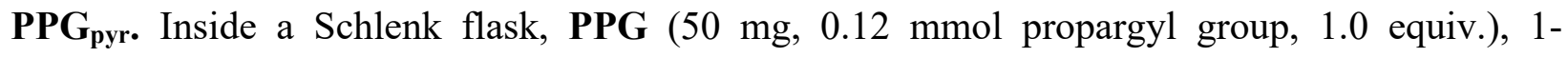
(azidomethyl)pyrene (47 mg, $0.18 \mathrm{mmol}, 1.5$ equiv.), $\mathrm{CuSO}_{4}(3.9 \mathrm{mg}, 0.025 \mathrm{mmol}, 0.20$ equiv.) and (+)-sodium L-ascorbate ascorbate $(5.0 \mathrm{mg}, 0.020 \mathrm{mmol}, 0.20$ equiv.) were combined. After the addition of DMF $(5.0 \mathrm{~mL})$, the flask was heated at $40{ }^{\circ} \mathrm{C}$ for $17 \mathrm{~h}$. The crude product was then cooled to $20^{\circ} \mathrm{C}$ and passed through a silica plug to remove excess copper. The pure product was isolated after dialysis against DMF (MWCO $=6 \mathrm{~kg} / \mathrm{mol} ; 2$ cycles) and ultrapure water ( 2 cycles, note that the polymer precipitates). Yield: 53\%. ${ }^{1} \mathrm{H}$ NMR (400 MHz, $\left.\mathrm{CDCl}_{3}, \delta\right): 8.33-7.34$ (m, 2.0 H), 6.10-5.56 (m, 1.0 H), 5.31-4.82 (m, $0.31 \mathrm{H}) 4.32-3.86(\mathrm{~m}, 1.3 \mathrm{H}), 1.33-0.76(\mathrm{~m}, 2.6 \mathrm{H})$. SEC: $\mathrm{M}_{\mathrm{n}}=10.6 \mathrm{~kg} / \mathrm{mol}, \mathrm{M}_{\mathrm{w}}=35.2 \mathrm{~kg} / \mathrm{mol}, D=3.31$.

\section{${ }^{1} \mathrm{H}$ NMR spectroscopy depolymerization studies of $\mathrm{PEtG}_{\mathrm{UV}}$}

The polymer $(20 \mathrm{mg})$ was dissolved in a $\mathrm{CD}_{3} \mathrm{CN} / \mathrm{D}_{2} \mathrm{O}$ mixture $(9 / 1,1.2 \mathrm{~mL})$ at $21{ }^{\circ} \mathrm{C}$. The solution was then transferred into two NMR tubes, and the tubes were promptly sealed. One tube was exposed to UV light ( $450 \mathrm{~W}$ bulb, $2.8 \mathrm{~mW} / \mathrm{cm}^{2}$ of UVA radiation) for $30 \mathrm{~min}$ to initiate the removal 
of the photolabile end-cap. The other NMR tube was kept in dark and was analyzed as a control sample for measuring any background polymer degradation. ${ }^{1} \mathrm{H}$ NMR spectra were recorded at defined intervals $(0,1,3,5$, and $24 \mathrm{~h})$ to monitor the depolymerization.

\section{Fluorescence of pyrene}

In a $10 \mathrm{~mL}$ volumetric flask, $1.5 \mathrm{mg}$ of $\mathbf{P P G}_{\text {pyr }}$ was dissolved in $9 / 1 \mathrm{CH}_{3} \mathrm{CN} /$ water. After being degassed by bubbling $\mathrm{N}_{2}$ through for $10 \mathrm{~min}$, it was placed inside a quartz cuvette for analysis. The emission spectrum was recorded using an excitation wavelength of $341 \mathrm{~nm}$, emission range of 351-800 nm, and a slit width of $5 \mathrm{~nm}$ using a QM-4 SE spectrometer from Photon Technology International. The sample was then irradiated with a UV light for $30 \mathrm{~min}$ as described for the depolymerization study, and incubated for $24 \mathrm{~h}$ before recording the emission spectrum of the depolymerized sample.

\section{RESULTS AND DISCUSSION}

Improving the PEtG design for transesterification reactions. So far, many previously reported self-immolative PEtGs had carbonate-containing end-groups. ${ }^{20,25,50-51}$ Hence, we started our study

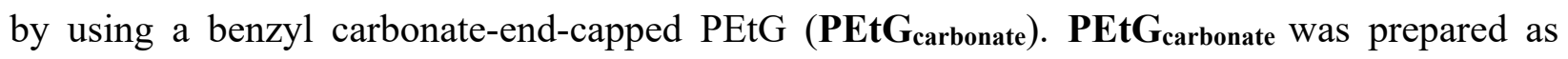
previously reported, ${ }^{40}$ with an $\mathrm{M}_{\mathrm{n}}$ of $27.6 \mathrm{~kg} / \mathrm{mol}, \mathrm{M}_{\mathrm{w}}=35.6 \mathrm{~kg} / \mathrm{mol}$, and $D=1.29$ (Scheme 1a). To probe the reactivity of PEtG in the transesterification reaction, a combination of $\mathbf{P E t} \mathbf{G}_{\text {carbonate }}$ with benzyl alcohol (10 equiv.) and $\operatorname{TBD}(0.2$ equiv. $)$ was heated at $100{ }^{\circ} \mathrm{C}$ for $48 \mathrm{~h}$. Benzyl alcohol was selected because of its high boiling point. In addition, peaks in the ${ }^{1} \mathrm{H}$ NMR spectrum of the expected poly(benzyl glyoxylate) (PBnG) product should not overlap with those of the starting PEtG $_{\text {carbonate, allowing the reaction conversion to be easily assessed. However, no polymer could }}$ 
be isolated after the reaction, suggesting that $\mathbf{P E t G}_{\text {carbonate }}$ didn't survive the transesterification reaction.

a)

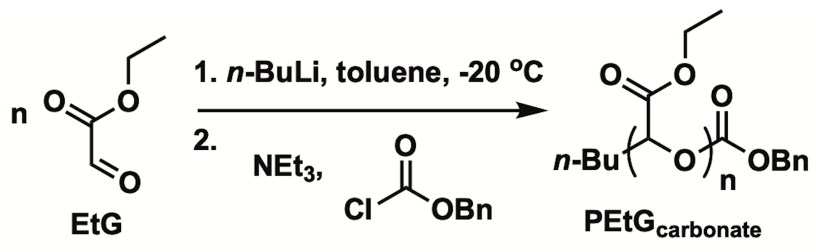

b)

Depolymerization

Nucleophilic cleavage

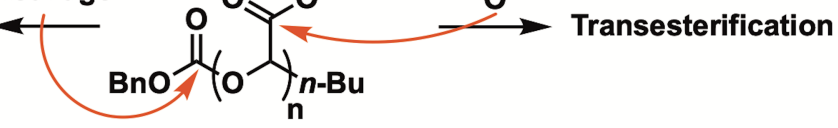

c)

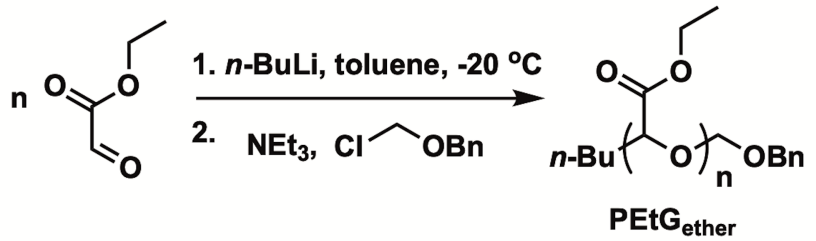

d)

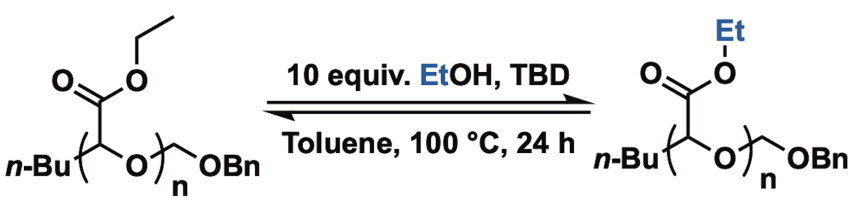

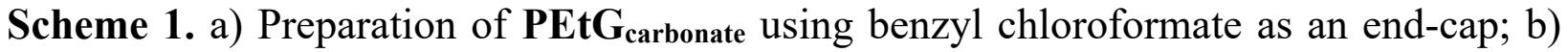
Possible pathways for the reaction of alcohols with PEtG $_{\text {carbonate }}$ leading to either transesterification or depolymerization; c) Preparation of $\mathbf{P E t G}_{\text {ether; }}$ d) Testing the stability of $\mathbf{P E t G}_{\text {ether }}$ under the transesterification reaction conditions.

To investigate the TBD-induced depolymerization further, $\mathbf{P E t G}_{\mathbf{c a r b o n a t e}}$ was heated at 100 ${ }^{\circ} \mathrm{C}$ in toluene, with ethanol (10 equiv.) and TBD (0.2 equiv.) for $24 \mathrm{~h}$. Samples were analyzed by SEC at different time points during the reaction. Ethanol was selected for this experiment because transesterification should lead to an unaltered SEC elution profile if the polymer did not depolymerize during the reaction. However, the SEC traces revealed that the intensity of the PEtG 
peak decreased over time (Figure 2a), confirming that $\mathbf{P E t G}_{\text {carbonate }}$ rapidly degraded under the reaction conditions. This degradation can be attributed to TBD-catalyzed nucleophilic attack on the carbonates (Scheme 1b). While carbonates may be less reactive than the pendent esters, even a single carbonate cleavage can lead to the depolymerization of an entire polymer chain.
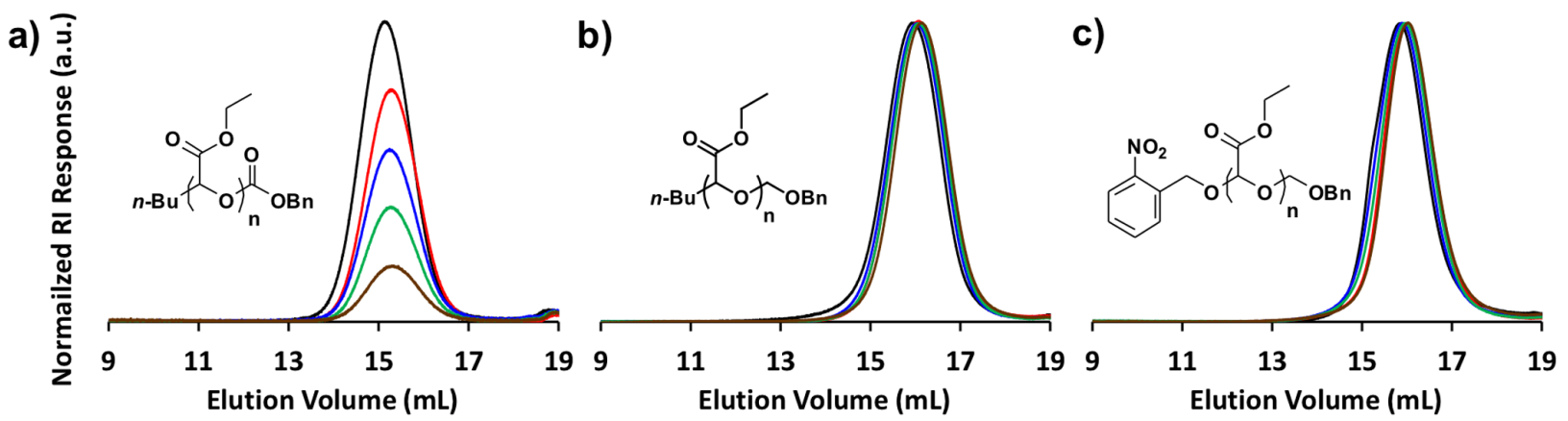

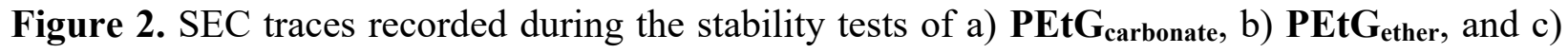

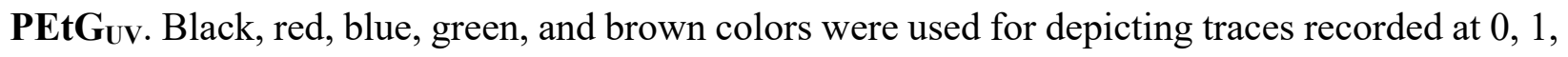
3, 6, and $24 \mathrm{~h}$, respectively. While $\mathbf{P E t G}_{\text {carbonate }}$ was degraded under the transesterification conditions, PEtG $_{\text {ether }}$ and PEtG $_{\mathbf{U V}}$ were stable.

To address the challenge of carbonate stability, ether end-caps were investigated. Triphenylmethyl ethers were previously used to cap PEtG for admidation reactions to produce polyglyoxylamides. ${ }^{33}$ However, triphenylmethyl end-capped PEtGs have limited thermal stability, ${ }^{52}$ and depolymerized upon heating at $100{ }^{\circ} \mathrm{C}$ for $24 \mathrm{~h}$. We also explored capping with various benzyl halides, but the end-capping reactions did not proceed. We attribute this low reactivity to the tight ion pairing between $\mathrm{Li}^{+}$and the alkoxide terminus of the polymer. ${ }^{53}$ On the other hand, chloromethyl benzyl ether $(\mathrm{BOMCl})$ was more reactive than benzyl halides and successfully end-capped PEtG by an ether linkage (Scheme 1c). 
The anionic polymerization of EtG was initiated with $n$-BuLi in toluene. ${ }^{40} \mathrm{BOMCl}$ was added at $-20^{\circ} \mathrm{C}$, and the resulting mixture was kept at $-20^{\circ} \mathrm{C}$ for $24 \mathrm{~h}$ to favor a high end-capping yield. The resulting $\mathbf{P E t} \mathbf{G}_{\text {ether }}$ had an $\mathrm{M}_{\mathrm{n}}$ of $13.9 \mathrm{~kg} / \mathrm{mol}, \mathrm{M}_{\mathrm{w}}=18.1 \mathrm{~kg} / \mathrm{mol}, \nexists=1.29$, and $\mathrm{DP}_{\mathrm{n}}=$ 136 based on SEC, consistent with the $\mathrm{DP}_{\mathrm{n}}$ calculated by ${ }^{1} \mathrm{H}$ NMR end-group analysis, i.e., $\mathrm{DP}_{\mathrm{n}}=$ 122 (Figure S2). This close accordance confirmed that the polymer chains were initiated from $n$ BuLi. However, the experimental $\mathrm{DP}_{\mathrm{n}}$ was lower than the targeted $\mathrm{DP}_{\mathrm{n}}$, i.e., 200. It is unlikely that the lower $\mathrm{DP}_{\mathrm{n}}$ arose from incomplete polymerization of monomer as we have previously found that the equilibrium ratio of polymer:monomer is $98: 2$ at $-20{ }^{\circ} \mathrm{C}$, and that the polymerization was complete in 10 min or less. ${ }^{40}$ Instead, it can likely be attributed to the low reactivity of BOMCl at $-20{ }^{\circ} \mathrm{C}$. End-capping may have begun when the polymerization mixture was gradually warming to $20^{\circ} \mathrm{C}$ and partial depolymerization had occurred. Indeed, considerable traces of EtG (12 mol\%) and ethyl glyoxylate hydrate (EtGH) (22 mol\%) were observed in the ${ }^{1} \mathrm{H}$ NMR spectrum of the concentrated crude polymerization mixture (Figure S1). However, as $\mathbf{P E t G}_{\text {ether }}$ was isolated with a satisfactory yield/molar mass, and our goal was primarily to investigate stability of the polymer, we continued our studies with $\mathbf{P E t G} \mathbf{G}_{\text {ether }}$. The stability tests performed on $\mathbf{P E t G} \mathbf{G}_{\text {carbonate }}$ were repeated for $\mathbf{P E t G}$ ether $($ Scheme 1d). The main peak corresponding to $\mathbf{P E t G}$ ether retained its intensity even after $24 \mathrm{~h}$ (Figure 2b), supporting our hypothesis that the carbonate linkers were responsible for the low stability of $\mathbf{P E t G} \mathbf{G}_{\text {carbonate }}$ and that PEtGs with carbonate-free end-caps can tolerate the transesterification reaction conditions.

$\mathrm{BOMCl}$ is an inexpensive regent that conveniently yielded $\mathbf{P E t} \mathbf{G}_{\text {ether }}$, but this polymer does not exhibit the desired stimuli-responsive properties. Although the polyacetal backbone of $\mathbf{P E t G}_{\text {ether }}$ is in principle acid-responsive, the adjacent electron-withdrawing ethyl ester groups make the acetals quite resistant to cleavage under acidic conditions. For example, benzyl carbonate 
end-capped PEtG underwent less than 5\% depolymerization over 48 days in $0.5 \mathrm{M}$ acetic acid. ${ }^{50}$ Therefore, we targeted a UV-responsive PEtG with carbonate-free end-caps to continue this study. 2-nitrobenzyl alcohol was lithiated using (TMS) $)_{2} \mathrm{NLi}$, which is a strong non-nucleophilic base. Using the resulting anionic alkoxide as an initiator and $\mathrm{BOMCl}$ as an end-cap, PEtGuv with an asymmetric design including UV-responsive and non-responsive end-caps (i.e., 2-nitrobenzyl and benzyl ether groups, respectively) was prepared (Scheme 2a).

a)

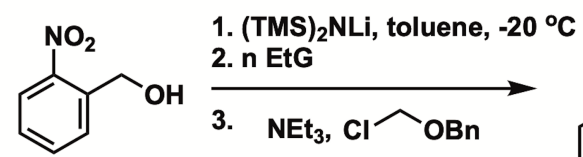

b)<smiles>CCOC(=O)C(C)OC(C)OCc1ccccc1[N+](=O)[O-]</smiles>

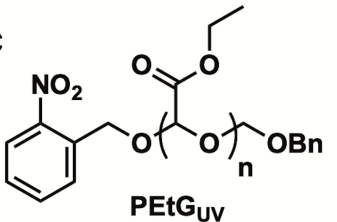

PEtG Uv

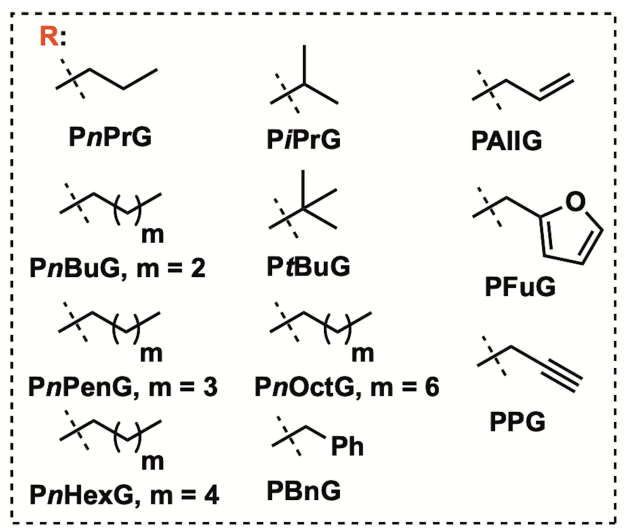

Scheme 2. a) Preparation of PEtG $\mathbf{U V}$ and b) transesterification of PEtG $\mathbf{U V}$ using different alcohols.

PEtG $_{\text {uv was purified similarly to }} \mathbf{P E t G}_{\text {ether }}$ and then analyzed by ${ }^{1} \mathrm{H}$ NMR spectroscopy and SEC. For end-group analysis, the integration of aromatic peaks of the 2-nitrobenzyl group were compared with that of the peak at $5.6 \mathrm{ppm}(\mathrm{CH}$ of the backbone) (Figure S3). This analysis suggested $\mathrm{DP}_{\mathrm{n}}=226$, which is similar to the targeted $\mathrm{DP}_{\mathrm{n}}$ and the $\mathrm{DP}_{\mathrm{n}}$ of 236 that was determined by SEC. The stability test of PEtGuv revealed that PEtGuv had a stability comparable with PEtG $_{\text {ether }}$ (Figure 2c).

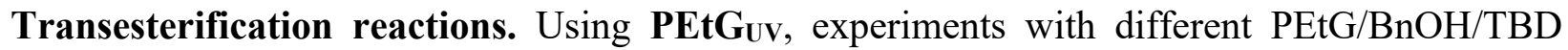
ratios, temperatures, and reaction times were conducted (Table S1, Figure S4). These experiments showed that heating at $100{ }^{\circ} \mathrm{C}$ was essential for good conversions, compared to 20 and $60{ }^{\circ} \mathrm{C} .0 .2$ 
equivalents of TBD per ester led to higher conversion than 0.1 equivalents but no benefits were achieved at higher loadings. A $17 \mathrm{~h}$ reaction time led to full conversion in the case of PBnG. In addition, while 1.5 equiv. of benzyl alcohol per pendent ester was sufficient for $>95 \%$ transesterification of PMA with benzyl alcohol using $\mathrm{TBD},{ }^{49}$ a higher stoichiometric excess was required for PEtG. This may be due to the lower reactivity of the ethyl esters or due to the different polymer backbones. A typical transesterification reaction involved combining a PEtG with an alcohol (10 equiv.) and catalytic TBD ( 0.2 equiv.) in dry toluene. The resulting solutions were then heated at $100{ }^{\circ} \mathrm{C}$ for $17 \mathrm{~h}$. After cooling to $20^{\circ} \mathrm{C}$, the solutions were diluted with $\mathrm{CH}_{2} \mathrm{Cl}_{2}$ and washed with an $\mathrm{HCl}$ solution to remove TBD. Depending on the solubility of the alcohols and resulting PGs, pure PGs were isolated by dissolving the residues in $\mathrm{CH}_{2} \mathrm{Cl}_{2}$ and either precipitating the polymers from pentane, or alternatively via dialysis against acetone.

To study the structure-reactivity relationships of alcohols in the transesterification of PEtG, $\mathbf{P E t G}_{\mathbf{u v}}$ was subjected to the transesterification with different alcohols, including $n$-propanol, $i$ propanol, $n$-butanol, $t$-butanol, $n$-pentanol, $n$-hexanol, $n$-octanol, and benzyl alcohol (Scheme 2b, Table 1). PnPrG, PiPrG, PnBug, PPenG, PHexG, POctG, and PBnG were isolated in yields of $61-70 \%$ and exhibited peaks associated with the newly introduced ester groups in their ${ }^{1} \mathrm{H}$ NMR spectra (Figures S5-S11). To calculate the conversion percentages, $\mathrm{CH}$ peaks from the polymer backbone were used as NMR handles and their integrals were fixed at 1.0 because their chemical shifts did not change by altering the pendent ester groups (Figure 3). With increasing the conversion, the integrations of $\mathrm{CH}_{3}$ peaks corresponding to the ethyl ester groups ( $c a .1 .3 \mathrm{ppm}$ ) decreased. For most polymers (exceptions are PiPrG and PBnG as described Figures 3c, S6, S11) a new $\mathrm{CH}_{3}$ peak appeared upfield ( $\left.c a .0 .9 \mathrm{ppm}\right)$ and its integration was used to calculate the conversion percentage using equation 1 . 
Conversion $\%=100 \times\left(\right.$ integration of $\mathrm{CH}_{3}$ peak from alkyl ester) $/ 3 \quad$ (equation 1$)$
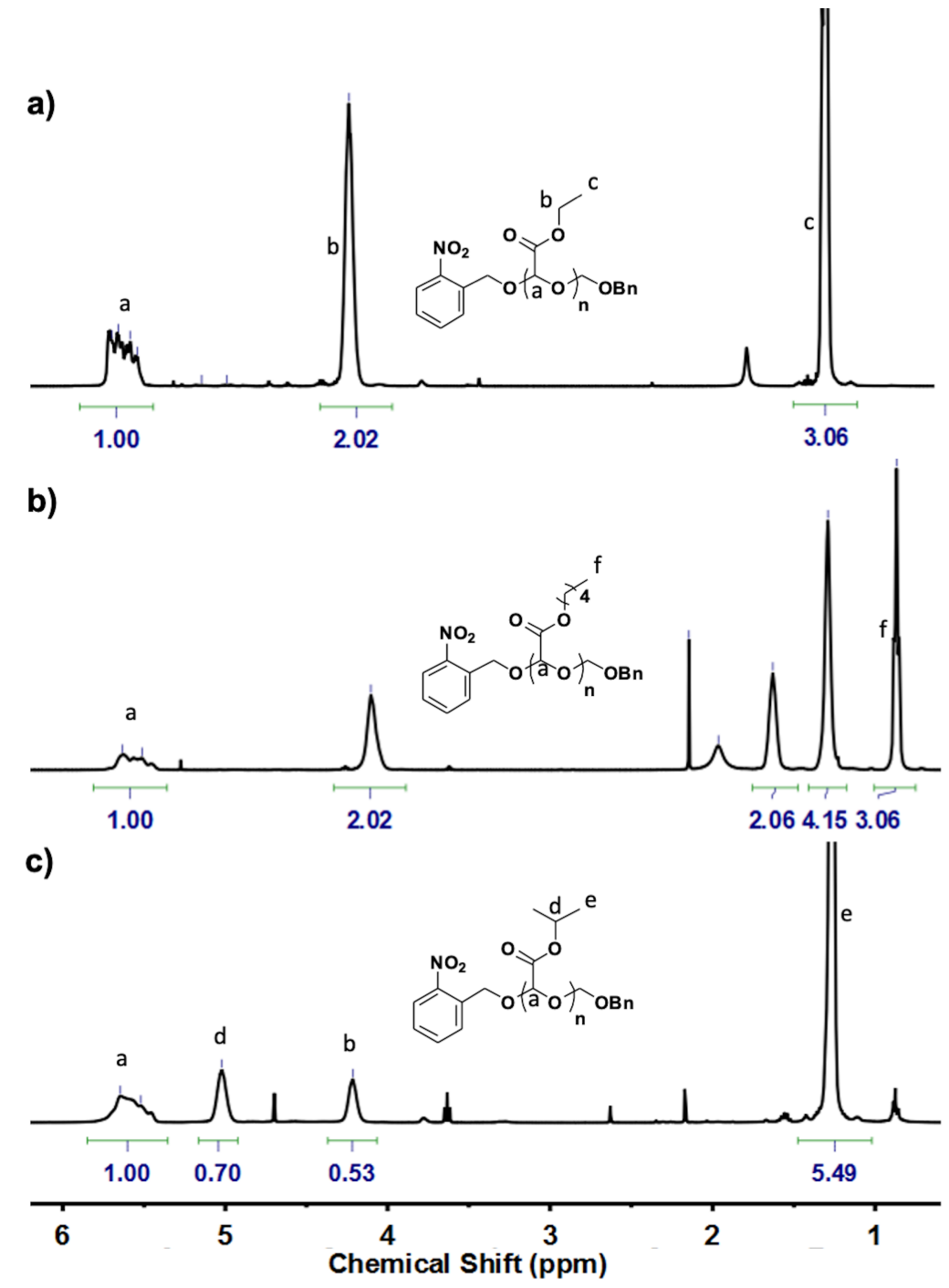

Figure 3. Overlay of NMR spectra of a) $\mathbf{P E t G}_{\mathbf{u v}}$; b) PnHexG; c) PiPrG showing how conversion could be calculated by fixing the backbone $\mathrm{CH}$ peak integral to 1.0 (labeled a), and then integrating the $\mathrm{CH}_{3}$ peak from the resulting alkyl ester for PnHexG (labeled f). For PiPrG, due to overlap of the $\mathrm{CH}_{3}$ peak in the starting material and the product (labeled e), the conversion was calculated based on the appearance of the new peak corresponding to the $\mathrm{CH}$ of the isopropyl ester (labeled d). 
For the primary alcohols, conversions greater than 95\%, were observed (Table 1). $i$ Propanol, a secondary alcohol, showed a 70\% conversion and $t$-butanol did not react under the transesterification reaction conditions. These large differences in conversion revealed the significant impact of the steric bulk surrounding the hydroxyl group on its reactivity. After confirming the conversion by ${ }^{1} \mathrm{H}$ NMR spectroscopy, the resulting pure polymers were analyzed by SEC (Figure 4a, Table 1). All of the transesterified polymers had elution profiles very similar to that of the starting PEtGuv. When combined with the SEC results for the transesterification reaction with ethanol (Figure 2c), these results suggest that their macromolecular structures were not substantially altered during the reaction and purification steps.

Table 1. SEC characterization data and reaction conversions for PGs.

\begin{tabular}{|c|c|c|c|c|c|c|}
\hline Polymer & $\begin{array}{l}\text { Conversion } \\
\qquad(\%)^{a}\end{array}$ & $\begin{array}{c}M_{\mathrm{n}} \\
(\mathrm{kg} / \mathrm{mol})^{b}\end{array}$ & $\begin{array}{c}M_{\mathrm{w}} \\
(\mathrm{kg} / \mathrm{mol})^{b}\end{array}$ & $\boldsymbol{\oplus}^{b}$ & $\begin{array}{c}T_{g} \\
\left({ }^{\circ} \mathbf{C}\right)^{d}\end{array}$ & $\begin{array}{c}T_{o} \\
\left({ }^{\circ} \mathrm{C}\right)^{e}\end{array}$ \\
\hline PEtG & - & 27.6 & 35.6 & 1.29 & -4 & 211 \\
\hline PEtG $_{\text {Ether }}$ & - & 14.0 & 18.1 & 1.29 & -10 & 224 \\
\hline PEtGuv $_{\text {Un }}$ & - & 24.1 & 29.9 & 1.24 & -12 & 223 \\
\hline PnPrG & $>95$ & 23.0 & 35.8 & 1.56 & -21 & 121 \\
\hline PiPrG & 70 & 15.8 & 28.0 & 1.77 & 3 & 136 \\
\hline PnBuG & $>95$ & 22.6 & 35.0 & 1.55 & -33 & 162 \\
\hline PtBuG & No reaction & - & - & - & - & - \\
\hline
\end{tabular}


$\begin{array}{lllllll}\text { PPenG } & >95 & 22.6 & 33.2 & 1.46 & -41 & 158\end{array}$

$\begin{array}{lllllll}\text { PHexG } & >95 & 26.4 & 44.1 & 1.67 & -46 & 169\end{array}$

$\begin{array}{lllllll}\text { POctG } & >95 & 28.9 & 54.1 & 1.87 & -47 & 158\end{array}$

$\begin{array}{lllllll}\text { PBnG } & >95 & 18.8 & 29.4 & 1.57 & 2 & 142\end{array}$

$\begin{array}{ccccccc}\text { PAIIG } & 25 & 20.2 & 31.3 & 1.55 & -7 & 168 \\ \text { PFuG } & 15 & 21.7 & 35.8 & 1.65 & 4 & 169 \\ \text { PPG } & 27 & 20.2 & 33.4 & 1.65 & 2 & 166 \\ \text { PPG }_{\text {pyr }} & 100^{c} & 10.6 & 35.2 & 3.31 & \mathrm{~N} / \mathrm{A}^{f} & \mathrm{~N} / \mathrm{A}^{f}\end{array}$

${ }^{a}$ Calculated using ${ }^{1} \mathrm{H}$ NMR spectra of the purified PGs. ${ }^{b}$ Obtained in THF using calibration $v s$.

PMMA standards. ${ }^{c}$ Relative to the parent PPG. ${ }^{d}$ Calculated using DSC. ${ }^{e}$ Calculated using TGA. $f_{\text {Not measured. }}$
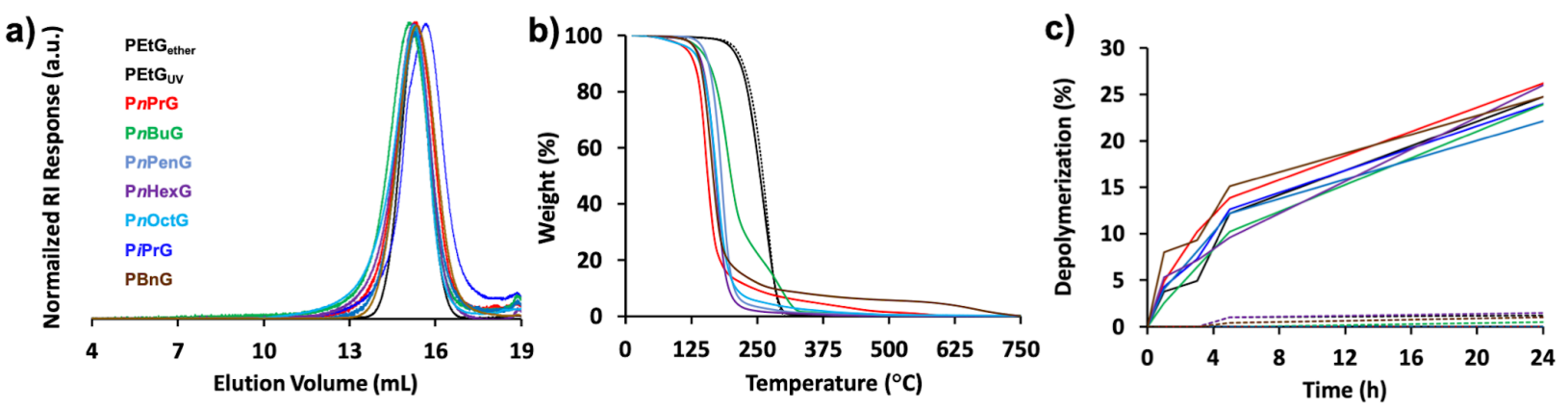

Figure 4. a) Size exclusion chromatograms for PEtGuv, PnPrG, PiPrG, PnBuG, PnPenG, PnHexG, PnOctG, and PBnG; b) Thermogravimetric analyses for the same polymers and in addition $\mathbf{P E t G}_{\text {ether }}$ (dashed black line); c) Depolymerization of polymers dissolved in $9 / 1$ $\mathrm{CD}_{3} \mathrm{CN} / \mathrm{D}_{2} \mathrm{O}$, then either irradiated with UV-light (solid lines) or kept in dark (dashed lines), and 
monitored by ${ }^{1} \mathrm{H}$ NMR spectroscopy. Note: depolymerization $\%$ was calculated relative to the depolymerization amount observed for the parent $\mathbf{P E t G}_{\mathbf{U V}}$ in $24 \mathrm{~h}$.

As the polyglyoxylates prepared in this study were all new in terms of the pendent groups and/or end-caps, they were analyzed using DSC and TGA to investigate their structure-property relationships. TGA showed that $\mathbf{P E t G}$ Uv and $\mathbf{P E t G}_{\text {ether }}$ had very similar onset of decomposition temperatures $\left(T_{o}\right)$ of about $224^{\circ} \mathrm{C}$ (Table 1, Figure $4 \mathbf{b}$ ), $\sim 13{ }^{\circ} \mathrm{C}$ higher than that of PEtG $\mathbf{G}_{\text {carbonate. }}$ This difference can likely be attributed to the higher thermal stability of ether end-caps compared to the carbonate end-caps. The new polyglyoxylate derivatives exhibited lower $T_{o}$ values, $c a .150$ ${ }^{\circ} \mathrm{C}$ (Figure 4b). PEtG $\mathbf{U V}$ that was transesterified with ethanol under the same reaction conditions to regenerate PEtGuv was also found to have a lower $T_{o}$ (Figure S17). Although no significant impurities were observed in the NMR spectrum of the polymer, one possible explanation is that trace impurities such as $\mathrm{TBD}$ or $\mathrm{HCl}$ from the workup step may lead to reduced thermal stability. Polyphthalaldehydes are known to be highly sensitive to trace impurities. ${ }^{54-55}$ Another possibility is that the presence of trace water in the transesterification led to trace hydrolysis of the pendent esters, resulting in pendent carboxylic acids. These carboxylic acids may intramolecularly catalyze the cleavage of backbone acetals, as proposed by Belloncle et al. in the degradation mechanism of PEtG with non-triggerable end-caps. ${ }^{39}$ Most of the alcohols in this study were relatively dry as received from suppliers and were used without drying. However, when wet ethanol was used in initial attempts to regenerate $\mathbf{P E t G}_{\mathbf{U V}}$ by transesterification, the polymer completely depolymerized during the reaction. These results highlight the susceptibility of hydrolyzed PEtG to depolymerization. Thus, the thermal stabilities of the derivatives can likely be enhanced on a polymer-by-polymer basis through further purification and/or more rigorous exclusion of water from the reaction. 
DSC revealed that the glass transition temperatures $\left(T_{g}\right)$ of the polyglyoxylates derived from the linear alcohols decreased with increasing number of carbons of the parent alcohol, i.e., from -4 to $-47^{\circ} \mathrm{C}$ (Table 1, Figures S20-S26). This result was expected as the longer aliphatic chains would allow for increased segmental motion. In contrast, polyglyoxylates derived from non-linear alcohols exhibited higher $T_{g}$ s, i.e., 3 and $2{ }^{\circ} \mathrm{C}$ for PiPrG and PBnG respectively, as the rigidity and steric hindrance of the pendent groups can inhibit segmental motion. The recorded $T_{g}$ for $\mathbf{P n B u G}\left(-33^{\circ} \mathrm{C}\right)$ was quite consistent with what was previously reported, i.e., $T_{g}=-30{ }^{\circ} \mathrm{C}$, for poly(butyl glyoxylate) homopolymer which was directly synthesized from the monomer and capped with 6-nitroveratryl carbonate. ${ }^{20}$ As the only reported example of poly(benzyl glyoxylate) homopolymer had a very low molar mass (i.e., $\mathrm{M}_{\mathrm{n}}=2.1 \mathrm{~kg} / \mathrm{mol}$ ) and thermal properties of oligomers and polymers are typically different, a similar comparison was not possible for PBnG.

Depolymerization studies. PEtGuv was expected to be responsive to UV light (Scheme 3). The backbone of PEtG has previously been shown to be stable to irradiation with UV light. ${ }^{20,25}$ To assess whether PEtG $_{\mathbf{U v}}$ and the resulting PGs showed UV-responsive depolymerization behaviour due to end-cap cleavage, ${ }^{1} \mathrm{H}$ NMR depolymerization studies were carried out, except for POctG due to its poor solubility under the depolymerization conditions. The PGs were dissolved in a 9/1 mixture of $\mathrm{CD}_{3} \mathrm{CN} / \mathrm{D}_{2} \mathrm{O}$ then split into 2 samples. One sample was irradiated for 30 minutes with a UV light and the other one was kept in dark (control sample). Over $24 \mathrm{~h}$, the samples were analyzed by ${ }^{1} \mathrm{H}$ NMR spectroscopy, at different time intervals (Figures $4 \mathbf{c}$ and $\mathbf{S 3 2}-\mathbf{S 4 5}$ ). The depolymerization was quantified based on the relative integrations of the peak corresponding to the backbone methine $\mathrm{CH}$, at $c a .5 .6 \mathrm{ppm}$, and the peak corresponding to the methine $\mathrm{CH}$ group of the depolymerization product (corresponding glyoxylate hydrate), at ca. 5 ppm over $24 \mathrm{~h}$ 
(Figure S33). All of the irradiated polymers depolymerized at similar rates to one another and to the same extent as PEtGuv. In contrast, the non-irradiated (control) samples showed negligible depolymerization amounts $(<2 \%)$. These results showed that the TBD catalyzed transesterification reaction did not alter the structure of the end-cap, allowing the stimuli-responsive properties to be retained. In addition, the depolymerization rates were determined by the nature of the backbone/end-group and not the pendent groups.

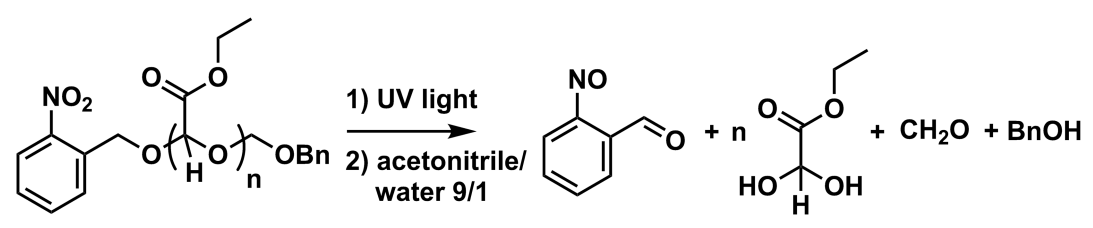

Scheme 3. UV-light triggered depolymerization of PEtGuv.

Synthesis and characterization of polyglyoxylates with functional groups. To further demonstrate the versatility of the transesterification method for PEtG, we employed several functional alcohols including allyl, propargyl and furfuryl alcohol (Scheme 2), which gave PGs suitable for click chemistry and applications such as labeling, sensing, and network formation. We only employed 0.5 equivalents of the corresponding alcohols as typically for such applications a small percentage of functional groups is sufficient. This method gave the targeted partiallyconverted PAllG, PPG, and PFuG with 25, 27, and 15\% conversion respectively based on the integrations of peaks corresponding to the new functional groups in the ${ }^{1} \mathrm{H}$ NMR spectra (Table 1, Figures S12-S14). SEC analysis showed that the polymeric structures were retained with similar retention times to PEtG $_{\mathbf{U}}$ (Table 1, Figure S18). Like for the PGs functionalized with pendent alkyl and benzyl esters, TGA studies showed that PAllG, PPG, and PFuG had $T_{o}$ values lower than that of the starting PEtGuv (Figure S19). DSC thermograms demonstrated that the $T_{g} \mathrm{~S}$ of 
these random copolymers were slightly higher than that of the parent PEtGuv probably due to the higher rigidity of the newly introduced ester groups compared to the original ethyl ester groups (Table 1, Figures S29-S31).

The utility of the functional handles was also demonstrated. We chose PPG as a precursor and conducted a copper assisted azide-alkyne click ( $\mathrm{CuACC})$ reaction to install pyrene as a fluorescent group. For the click reaction, PPG was combined with $\mathrm{CuSO}_{4}$, sodium ascorbate, and an excess amount of 1-(azidomethyl)pyrene (Py-N3), in dry DMF (Scheme 4). The crude product was then dialyzed to remove excess pyrene and residual copper species. In the ${ }^{1} \mathrm{H}$ NMR spectrum of pure $\mathbf{P P G}_{\mathbf{p y r}}$, the aromatic protons of pyrene gave rise to a broad peak at ca. $7.9 \mathrm{ppm}$ in addition to its methylene peak which appeared at ca. $5.1 \mathrm{ppm}$ (Figure S15). This conversion was also confirmed by FTIR spectroscopy as the alkyne groups of PPG led to an alkyne C-H absorption band at $3300 \mathrm{~cm}^{-1}$ (Figure 5a). This band was absent in the FTIR spectrum of PPG 5a). Furthermore, a strong peak due to aromatic $\mathrm{C}-\mathrm{H}$ stretching at $3040 \mathrm{~cm}^{-1}$ appeared in the spectrum of $\mathbf{P} \mathbf{P G} \mathbf{p}_{\mathbf{p y r}}$. SEC confirmed that $\mathbf{P} \mathbf{P} \mathbf{G}_{\mathbf{p y r}}$ still retained a polymeric structure but its SEC trace was skewed towards low elution-volumes, likely due to its poor solubility in THF (Figure 5b). Strong interactions between the pendent pyrene groups may limit the solubility.

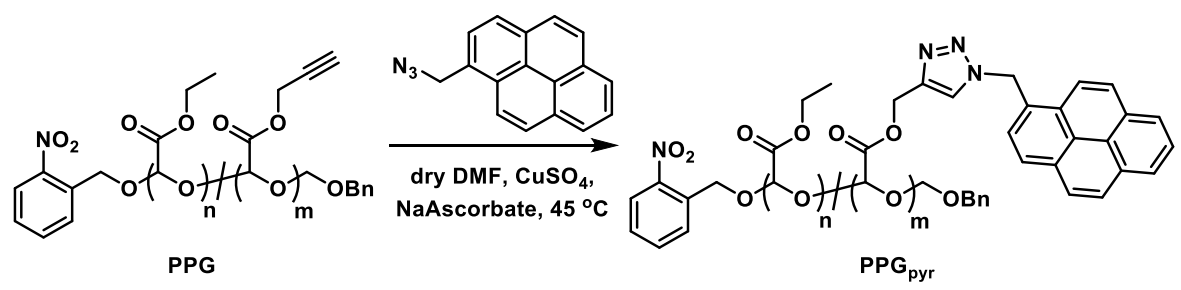

Scheme 4. Click reaction of PPG with $\mathbf{P y r}-\mathbf{N}_{3}$. 

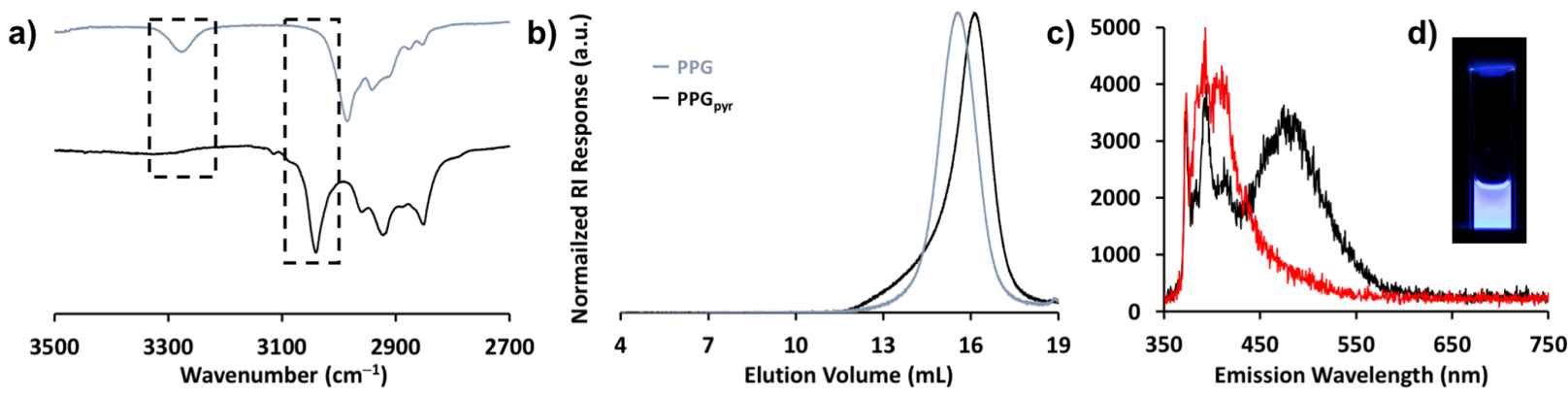

Figure 5. a) Alkyne region of the FTIR spectra recorded for PPG and PPG $\mathbf{P y r}_{\text {showing }}$ disappearance of the alkyne $\mathrm{C}-\mathrm{H}$ stretch and appearance of a new peak corresponding to aromatic C-H stretching; b) SEC traces for PPG and $\mathbf{P P G}$ pyr; c) Emission spectra of $\mathbf{P P G}$ pyr before (black line) and after (red line) UV-light irradiation recorded in $\mathrm{MeCN} / \mathrm{H}_{2} \mathrm{O}$ : 9/1; d) $\mathbf{P} \mathbf{P G}$ pyr sample used for emission spectroscopy.

Pyrene is sensitive to its local environment. In particular, when pyrene units are bound in a close proximity, excited state dimers, referred to as excimers can form. ${ }^{56}$ A pyrene excimer emits at $c a .475 \mathrm{~nm}$, while a single pyrene ("locally excited" or monomer) emits with two maxima at $c a$. 360 and $375 \mathrm{~nm} .{ }^{57}$ Taking advantage of this phenomenon, we decided to test the potential for $\mathbf{P P G}_{\text {pyr }}$ serve as a sensor. It was expected that in dilute solution, pyrene excimers could be formed in the polymeric state, whereas depolymerization should lead to disappearance of these excimers. Thus, the conversion of pyrene excimers to monomer, detected by fluorescence spectroscopy, could in principle be used to "sense" end-cap cleavage and depolymerization. A dilute solution (3.6 $\times 10^{-4}$ M pyrene moieties in $\mathrm{CH}_{3} \mathrm{CN} / \mathrm{H}_{2} \mathrm{O}$ : 9/1) of $\mathbf{P} \mathbf{P G}_{\mathbf{p y r}}$ was prepared and degassed, and then its emission spectrum was obtained using an excitation wavelength of $341 \mathrm{~nm}$. A broad peak at $475 \mathrm{~nm}$ confirmed that the pyrene groups of $\mathbf{P} \mathbf{P G}_{\mathbf{p y r}}$ were preferentially in an excimer form as the integrity of $\mathbf{P P G}$ pyr kept them in close proximity, although the overall concentration of $\mathbf{P P G} \mathbf{G}_{\mathbf{p y r}}$ was very low (Figure 5c). The sample was then irradiated with UV-light and allowed to 
depolymerize for $24 \mathrm{~h}$. The sample was again excited at $341 \mathrm{~nm}$ to obtain an emission spectrum, which showed a dramatic decrease in the integration of the excimer peak while the released pyrene units gave rise to peaks at 360 and $375 \mathrm{~nm}$. This example suggests the capability of $\mathbf{P P G}_{\mathbf{p y r}}$ to serve as a sensor using the end-cap as a trigger and highlights the fact that many polyglyoxylates with functional groups, such as drug or dye moieties, which can't be directly synthesized from a glyoxylate monomer or tolerate the transesterification reaction, can be accessible using our strategy.

\section{CONCLUSIONS}

PEtG $_{\text {carbonate }}$ depolymerized upon heating in toluene with TBD at $100{ }^{\circ} \mathrm{C}$. However, PEtG $_{\text {ether }}$ and PEtG $_{\mathbf{U v}}$ with ether end-caps were stable to these TBD-mediated transesterification conditions. Transesterification reactions of $\mathbf{P E t G} \mathbf{U v}$ with $n$-propanol, $n$-butanol, $n$-pentanol, $n$-hexanol, $n$ octanol, provided the corresponding polyglyoxylates with conversions $>95 \%$. Secondary alcohols and tertiary alcohols including $i$-propanol and $t$-butanol resulted in lower or no conversion due to steric hindrance. ${ }^{1} \mathrm{H}$ NMR spectroscopy confirmed the structures of the new polyglyoxylates and SEC showed that the macromolecular nature of the parent PEtGuv was preserved in all of the products. Depolymerization studies revealed that all polyglyoxylates retained the self-immolative behavior of PEtG $\mathbf{U v}$ and changing the pendent ester groups did not have a noticeable effect on the depolymerization. TGA showed that the transesterification products had somewhat lower thermal stability than the starting polymer, likely due to trace impurities from the reaction or workup procedures or due to trace hydrolysis generating pendent carboxylic acids. This issue can likely be addressed through rigorous exclusion of water from the transesterification reaction and/or further purification of the polymers. In addition, DSC demonstrated that changing the pendent groups 
resulted in changes in the thermal properties as polyglyoxylates with $T_{g} \mathrm{~s}$ ranging from -47 to $3{ }^{\circ} \mathrm{C}$ for the different derivatives. To show that the number of polyglyoxylates accessible via the transesterification strategy can go beyond what is shown in this study, allyl, propargyl and furfuryl alcohols were used to prepare derivatives suitable for click chemistry. The CuAAC reaction of PPG with $\mathbf{P y r}-\mathbf{N}_{3}$ gave $\mathbf{P P G}_{\mathrm{pyr}}$ with potential for sensing applications, as successfully confirmed via fluorescence emission spectroscopy.

\section{ACKNOWLEDGEMENTS}

The authors thank Quinton Sirianni for performing the polymer thermal analyses and the Natural Sciences and Engineering Research Council of Canada (Discovery Grant 2016-04636; E. W. R. Steacie Memorial Fellowship to ERG: 507348-2017; Canada Graduate Scholarship for REY) for funding this work.

\section{SUPPORTING INFORMATION}

NMR and FTIR spectra, additional SEC and TGA data, DSC thermograms, NMR data from degradation studies.

\section{REFERENCES}

(1) van Heeswijk, E. P. A.; Kragt, A. J. J.; Grossiord, N.; Schenning, A. P. H. J. Environmentally Responsive Photonic Polymers. Chem. Commun. 2019, 55, 2880-2891.

(2) Hu, L.; Zhang, Q.; Li, X.; Serpe, M. J. Stimuli-Responsive Polymers for Sensing and Actuation. Mater. Horiz. 2019, 6, 1774-1793. 
(3) Mura, S.; Nicolas, J.; Couvreur, P. Stimuli-Responsive Nanocarriers for Drug Delivery. Nat. Mater. 2013, 12, 991-1003.

(4) Lambert, S.; Wagner, M. Environmental Performance of Bio-Based and Biodegradable Plastics: The Road Ahead. Chem. Soc. Rev. 2017, 46, 6855-6871.

(5) Sanchez-Hernandez, J. C.; Capowiez, Y.; Ro, K. S. Potential Use of Earthworms to Enhance Decaying of Biodegradable Plastics. ACS Sus. Chem. Eng. 2020, 8, 4292-4316.

(6) Doppalapudi, S.; Jain, A.; Domb, A. J.; Khan, W. Biodegradable Polymers for Targeted Delivery of Anti-Cancer Drugs. Expert Opin. Drug Deliv. 2016, 6, 891-909.

(7) Kim, S. W.; Petersen, R. V.; Feijen, J. Polymeric Drug Delivery Systems. Drug Design 2016, 10, 193-250.

(8) Mooney, D. J. Regenerative Medicine: Current Therapies and Future Directions. Proc. Natl. Acad. Sci. USA 2015, 112, 14452-14459.

(9) Langer, R.; Vacanti, J. Advances in Tissue Engineering. J. Pediatr. Surg. 2016, 51, 8-12.

(10) Roth, M. E.; Green, O.; Gnaim, S.; Shabat, D. Dendritic, Oligomeric, and Polymeric SelfLmmolative Molecular Amplification. Chem. Rev. 2016, 116, 1309-1352.

(11) Yardley, R. E.; Rabiee Kenaree, A.; Gillies, E. R. Triggering Depolymerization: Progress and Opportunities for Self-Immolative Polymers. Macromolecules 2019, 52, 6342-6360.

(12) Heffernan, M. J.; Murthy, N. Polyketal Nanoparticles: A New pH-Sensitive Biodegradable Drug Delivery Vehicle. Bioconjugate Chem. 2005, 16, 1340-1342. 
(13) Rickerby, J.; Prabhakar, R.; Ali, M.; Knowles, J.; Brocchini, S. Water-Soluble

Polyacetals Derived from Diphenols. J. Mater. Chem. 2005, 15, 1849-1856.

(14) Yan, Q.; Han, D.; Zhao, Y. Main-Chain Photoresponsive Polymers with Controlled Location of Light-Cleavable Units: From Synthetic Strategies to Structural Engineering. Polym.

Chem. 2013, 4, 5026-5037.

(15) Sagi, A.; Weinstain, R.; Karton, N.; Shabat, D. Self-Immolative Polymers. J. Am. Chem. Soc. 2008, 130, 5434-5435.

(16) DeWit, M. A.; Gillies, E. R. A Cascade Biodegradable Polymer Based on Alternating Cyclization and Elimination Reactions. J. Am. Chem. Soc. 2009, 131, 18327-18334.

(17) Olah, M. G.; Robbins, J. S.; Baker, M. S.; Phillips, S. T. End-Capped Poly(Benzyl Ethers): Acid and Base Stable Polymers That Depolymerize Rapidly from Head-to-Tail in Response to Specific Applied Signals. Macromolecules 2013, 46, 5924-5928.

(18) Seo, W.; Phillips, S. T. Patterned Plastics That Change Physical Structure in Response to Applied Chemical Signals. J. Am. Chem. Soc. 2010, 132, 9234-9235.

(19) Kaitz, J. A.; Diesendruck, C. E.; Moore, J. S. End Group Characterization of Poly(Phthalaldehyde): Surprising Discovery of a Reversible, Cationic Macrocyclization Mechanism. J. Am. Chem. Soc. 2013, 135, 12755-12761.

(20) Fan, B.; Trant, J. F.; Wong, A. D.; Gillies, E. R. Polyglyoxylates: A Versatile Class of Triggerable Self-Immolative Polymers from Readily Accessible Monomers. J. Am. Chem. Soc. 2014, 136, 10116-10123. 
(21) Lewis, G. G.; Robbins, J. S.; Phillips, S. T. Point-of-Care Assay Platform for Quantifying Active Enzymes to Femtomolar Levels Using Measurements of Time as the Readout. Anal.

Chem. 2013, 85, 10432-10439.

(22) Park, C. W.; Kang, S.-K.; Lopez Hernandez, H.; Kaitz, J. A.; Wie, D. S.; Shin, J.; Lee, O. P.; Sottos, N. R.; Moore, J. S.; Rogers, J. A.; White, S. R. Thermally Triggered Degradation of Transient Electronic Devices. Adv. Mater. 2015, 27, 3783-3788.

(23) Hernandez, H. L.; Kang, S.-K.; Lee, O. P.; Hwang, S.-W.; Kaitz, J. A.; Inci, B.; Park, C. W.; Chung, S.; Sottos, N. R.; Moore, J. S.; Rogers, J. A.; White, S. R. Triggered Transience of Metastable Poly(phthalaldehyde) for Transient Electronics. Adv. Mater. 2014, 26, 7637-7642.

(24) Lee, K. M.; Phillips, O.; Engler, A.; Kohl, P. A.; Rand, B. P. Phototriggered Depolymerization of Flexible Poly(phthalaldehyde) Substrates by Integrated Organic LightEmitting Diodes. ACS Appl. Mater. Interfaces 2018, 10, 28062-28068.

(25) Fan, B.; Gillies, E. R. Poly(ethyl glyoxylate)-Poly(ethylene oxide) Nanoparticles: Stimuli-Responsive Drug Release Via End-to-End Polyglyoxylate Depolymerization. Mol. Pharm. 2017, 14, 2548-2559.

(26) Gambles, M. T.; Fan, B.; Borecki, A.; Gillies, E. R. Hybrid Polyester Self-Immolative Polymer Nanoparticles for Controlled Drug Release. ACS Omega 2018, 3, 5002-5011.

(27) de Gracia Lux, C.; McFearin, C. L.; Joshi-Barr, S.; Sankaranarayanan, J.; Fomina, N.; Almutairi, A. Single UV or Near IR Triggering Event Leads to Polymer Degradation into Small Molecules. ACS Macro Lett. 2012, 1, 922-926. 
(28) Baker, M. S.; Kim, H.; Olah, M. G.; Lewis, G. G.; Phillips, S. T. Depolymerizable Poly(benzyl ether)-Based Materials for Selective Room Temperature Recycling. Green Chem. 2015, 17, 4541-4545.

(29) Fan, B.; Trant, J. F.; Yardley, R. E.; Pickering, A. J.; Lagugné-Labarthet, F.; Gillies, E. R. Photocontrolled Degradation of Stimuli-Responsive Poly(ethyl glyoxylate): Differentiating Features and Traceless Ambient Depolymerization. Macromolecules 2016, 49, 7196-7203.

(30) Lloyd, E. M.; Lopez Hernandez, H.; Feinberg, A. M.; Yourdkhani, M.; Zen, E. K.; Mejia, E. B.; Sottos, N. R.; Moore, J. S.; White, S. R. Fully Recyclable Metastable Polymers and Composites. Chem. Mater. 2019, 31, 398-406.

(31) Joo, W.; Wang, W.; Mesch, R.; Matsuzawa, K.; Liu, D.; Willson, C. G. Synthesis and Unzipping Polyester and a Study of Its Photochemistry. J. Am. Chem. Soc. 2019, 141, 1473614741.

(32) Kim, H.; Brooks, A. D.; DiLauro, A. M.; Phillips, S. T. Poly(carboxypyrrole)s that Depolymerize from Head to Tail in the Solid State in Response to Specific Applied Signals. J. Am. Chem. Soc. 2020, 142, 9447-9452.

(33) Sirianni, Q. E. A.; Rabiee Kenaree, A.; Gillies, E. R. Polyglyoxylamides: Tuning Structure and Properties of Self-Immolative Polymers. Macromolecules 2019, 52, 262-270.

(34) Ree, L. H. S.; Sirianni, Q. E. A.; Gillies, E. R.; Kelland, M. A. Systematic Study of Polyglyoxylamides as Powerful, High-Cloud-Point Kinetic Hydrate Inhibitors. Energy Fuels 2019, 33, 2067-2075. 
(35) Chen, E. K. Y.; McBride, R. A.; Gillies, E. R. Self-Immolative Polymers Containing Rapidly Cyclizing Spacers: Toward Rapid Depolymerization Rates. Macromolecules 2012, 45, $7364-7374$.

(36) Gnaim, S.; Shabat, D. Self-Immolative Chemiluminescence Polymers: Innate Assimilation of Chemiexcitation in a Domino-Like Depolymerization. J. Am. Chem. Soc. 2017, 139, 10002-10008.

(37) Schwartz, J. M.; Gourdin, G.; Phillips, O.; Engler, A.; Lee, J.; Abdulkadir, N. R.; Miller, R. C.; Sutlief, A.; Kohl, P. A. Cationic Polymerization of High-Molecular-Weight Phthalaldehyde-Butanal Copolymer. J. Appl. Polym. Sci. 2019, 136, 46921.

(38) DiLauro, A. M.; Robbins, J. S.; Phillips, S. T. Reproducible and Scalable Synthesis of End-Cap-Functionalized Depolymerizable Poly(phthalaldehydes). Macromolecules 2013, 46, $2963-2968$.

(39) Belloncle, B.; Burel, F.; Oulyadi, H.; Bunel, C. Study of the in Vitro Degradation of Poly(ethyl glyoxylate). Polym. Deg. Stability 2008, 93, 1151-1157.

(40) Rabiee Kenaree, A.; Gillies, E. R. Controlled Polymerization of Ethyl Glyoxylate Using Alkyllithium and Alkoxide Initiators. Macromolecules 2018, 51, 5501-5510.

(41) Engler, A.; Phillips, O.; Miller, R. C.; Tobin, C.; Kohl, P. A. Cationic Copolymerization of $o$-Phthalaldehyde and Functional Aliphatic Aldehydes. Macromolecules 2019, 52, 4020-4029.

(42) Kaitz, J. A.; Moore, J. S. Functional Phthalaldehyde Polymers by Copolymerization with Substituted Benzaldehydes. Macromolecules 2013, 46, 608-612. 
(43) DiLauro, A. M.; Lewis, G. G.; Phillips, S. T. Self-Immolative Poly(4,5-

dichlorophthalaldehyde) and Its Applications in Multi-Stimuli-Responsive Macroscopic Plastics. Angew. Chem. Int. Ed. 2015, 127, 6298-6303.

(44) Lutz, J. P.; Davydovich, O.; Hannigan, M. D.; Moore, J. S.; Zimmerman, P. M.; McNeil, A. J. Functionalized and Degradable Polyphthalaldehyde Derivatives. J. Am. Chem. Soc. 2019, $141,14544-14548$.

(45) Fan, B.; Yardley, R. E.; Trant, J. F.; Borecki, A.; Gillies, E. R. Tuning the Hydrophobic Cores of Self-Immolative Polyglyoxylate Assemblies. Polym. Chem. 2018, 9, 2601-2610.

(46) Belloncle, B.; Bunel, C.; Menu-Bouaouiche, L.; Lesouhaitier, O.; Burel, F. Study of the Degradation of Poly(ethyl glyoxylate): Biodegradation, Toxicity and Ecotoxicity Assays. $J$. Polym. Environ. 2012, 20, 726-731.

Baker, P. R. S.; Cramer, S. D.; Kennedy, M.; Assimos, D. G.; Holmes, R. P. Glycolate and Glyoxylate Metabolism in HEPG2 Cells. Am. J. Physiol.: Cell Physiol. 2004, 287, C1359C1365.

(48) Blasco, E.; Sims, M. B.; Goldmann, A. S.; Sumerlin, B. S.; Barner-Kowollik, C. 50th Anniversary Perspective: Polymer Functionalization. Macromolecules 2017, 50, 5215-5252.

(49) Easterling, C. P.; Kubo, T.; Orr, Zachary M.; Fanucci, G. E.; Sumerlin, B. S. Synthetic Upcycling of Polyacrylates through Organocatalyzed Post-Polymerization Modification. Chem. Sci. 2017, 8, 7705-7709. 
(50) Fan, B.; Trant, J. F.; Gillies, E. R. End-Capping Strategies for Triggering End-to-End Depolymerization of Polyglyoxylates. Macromolecules 2016, 49, 9309-9319.

(51) Fan, B.; Trant, J. F.; Hemery, G.; Sandre, O.; Gillies, E. R. Thermo-Responsive SelfImmolative Nanoassemblies: Direct and Indirect Triggering. Chem. Commun. 2017, 53, 1206812071.

(52) Fan, B.; Salazar, R.; Gillies, E. R. Depolymerization of Trityl End-Capped Poly(ethyl glyoxylate): Potential Applications in Smart Packaging. Macromol. Rapid Commun. 2018, 39, 1800173.

(53) Msayib, K. J.; Watt, C. I. F. Ion Pairing and Reactivity of Alkali Metal Aloxides. Chem. Soc. Rev. 1992, 237-243.

(54) Feinberg, A. M.; Lopez Hernandez, H.; Plantz, C. L.; Mejia, E. B.; Sottos, N. R.; White, S. R.; Moore, J. S. Cyclic Poly(phthalaldehyde): Thermoforming a Bulk Transient Material. ACS Macro Lett. 2018, 7, 47-52.

(55) Schwartz, J. M.; Phillips, O.; Engler, A.; Sutlief, A.; Lee, J.; Kohl, P. A. Stable, HighMolecular-Weight Poly(phthalaldehyde). J. Polym. Sci., Part A: Polym. Chem. 2017, 55, 11661172.

(56) Winnik, F. M. Photophysics of Preassociated Pyrenes in Aqueous Polymer Solutions and in Other Organized Media. Chem. Rev. 1993, 93, 587-614.

(57) Casier, R.; Gauthier, M.; Duhamel, J. Using Pyrene Excimer Fluorescence to Probe Polymer Diffusion in Latex Films. Macromolecules 2017, 50, 1635-1644. 